\title{
Studies on the Energy Properties and Fuel Potentials of Selected Indigenously Processed Plant-Based Bio-Resources Used as Sources of Sustainable Flame in North Central Nigerian Communities
}

\author{
*Gushit, J. S. Shimuan, J. T. Ajana, M. O. \\ Chemical/Petroleum Unit, Department of Science Laboratory Technology (SLT), \\ University of Jos, PMB 2084, Jos, Plateau State, Nigeria
}

\begin{abstract}
In this work, the stems of two matured shrubby plants identified as wild bitter leaf (Vernonia colorata) \& kenaf (Hibiscus canabinus) were studied for their energy properties and fuel potentials. The indigenously processed and dried stems of these plants have historically been used as sources of sustainable bright flame in communities within north central Nigeria. The two samples were collected, dried, pulverized and extracted using appropriate solvents to isolate the volatile combustible compounds believed to be responsible for the bright flame on combustion. The isolates are being purified to be detected using appropriate instrumentations such as GCMS and LCMS (ongoing). Prior to isolation, the physical energy properties which include; total volatile organic compounds (TVOC), fixed carbon, ash content, ultimate values, calorific value, moisture contents (MC) were determined. The gases emitted by these plants materials on combustion were also detected using multigas detector (Altair 5x Multigas). The results obtained indicate the concentrations of gases emitted such as $\mathrm{CO}, \mathrm{SOx}$ and, NOx from the processed substances on combusting are within acceptable standard limits set for these gases, which suggest it is environmentally friendly. The technology employed in making the plants provide more sustainable flame for the light will eventually be studied by collecting samples of substances used in the process (water, mud, algae) for characterization.
\end{abstract}

Keywords: Energy, fuel, bio-resources, sustainable flame

DOI: $10.7176 / \mathrm{JETP} / 9-6-02$

Publication date: August $31^{\text {st }} 2019$

\section{Introduction}

The looming global energy crisis has prompted the search for alternatively energy sources globally in recent times. This is attributed to daily energy demand from various works of life like schools, homes, business areas and industries. It is forecasted that global energy demand could rise to $50 \%$ by the year 2025, with major part of the increase in demand coming from emerging economies (Agbro and Ogie, 2010). Part of the approaches needed to solve the energy crisis is to explore and establish empirical evidences to indigenous skills and techniques that were used in the ancient time as sources of energy in some tropical African communities. For instance, common with the Mushere, Chakfem, Mchip, Mupun, Angas, Mwaghavul and many other communities in Central Nigeria is the use of locally processed stems of shrubby plants like kenaf (Hibiscus cannabinus) and wild biter leaf (Vernonia colorata). From the processed stem of these plants which these communities called 'giyam' they are able to get sustainable burning flame that provides bright light in dark places and their houses. These skills and technologists are fading away without exploring their potential which might eventually be the answer to the widely acclaimed global need for sustainable alternative energy source.

The indigenous process technology used by these communities involves harvesting the matured plants. This is eventually dried and dipped in muddy water for 4-5weeks, during which it is believed to have undergone some catalytic and microbial transformations (Figure 1). The processed stem has a very good combustion property as it is observed to burn continuously for some time with sustainable bright flame which acts as source of light in the dark with little smoke to pollute the environment. Like every other flammable material, it is expected that there should be some volatile components in the processed plant stem products which are responsible for the sustainable burning quality, unlike the unprocessed plant stem which does not produce such a sustainable bright flame. This is in line with an earlier work (Chaula et al., 2014), which confirmed that, those biomasses that contain a high content of volatile components, burn with a thick and bright flame. The aim of the research is to investigate the energy potential and the fuel properties of plants widely used as sources of sustainable flame by indigenous communities in North Central Nigeria.

\section{Methodology}

Hibiscus canabinus and Vernonia colorata were harvested around November and December when they were fully matured and sun-dried. After drying, the samples were soaked in muddy water for at least 5 weeks, debarked and sun-dry. The dried stems were crushed and ground with pestle and mortar. The pulverized samples 
were then sieved to obtain a particle size of $0.50-1.00 \mathrm{~mm}$. The following analysis were done on the samples based on methods adapted (Akowuah et al., 2012; Efomah and Gbabo, 2015; Saheed et al., 2015]; density/bulk density, moisture Contents, gross calorific value, ultimate analyses, volatile matter, ash content, fixed carbon, dry matter. Similarly, method used (Wang et al., 2014) was slightly modified for characterization of the volatile organic compounds (VOCs).

\section{Results and Discussion}

The proximate analysis of $H$. canabinus and $V$. colorata processed stems are presented in Figure 2 . The volatile matter content which is one of the parameter of interest in this research is $83.35 \%$ and $77.18 \%$ for the $H$. canabinus and $V$. colorata respectively. The relatively high volatile matter in both plants justify why they are widely used as sources of sustainable flame. Some researchers (Loo and Koppejan, 2008) opined that when the volatile matters detected is high; it signifies easy ignition and a proportionate increase in flame length. It also indicates that during combustion, most plants will volatilize and burn in the gaseous phase. However, the $H$. canabinus with volatile components of $83.35 \%$ will produce more flame. The relatively high dry matter contents of $85.00 \%$ for $H$. canabinus and $90.92 \%$ for $V$. colorata further justify the high combustion potentials of the plants.

Percentage ash content for both $H$. canabinus $(8.60 \%)$ and $V$. colorata $(4.65 \%)$ gives the amount of the inorganic matter left out after complete combustion. The ash content is a lot higher than European normal standard of $<1.5 \%$ for biomasses reported by Akowuah et al. (2012). While the moisture contents (MC) lies between $7.53 \%$ and $9.48 \%$ which is well below the limit of $10-12 \%$ recommended by Austria and German standards for fuel pellets and briquettes (DIN, 1996 and ONORM, 2003). The low MC enhances the ignition ability which further heightens the combustion quality and helps reduce objectionable smoke and toxic gases release (Godbout et al., 2012).

Fixed carbon contents were $8.69 \%$ for $V$ colorata and $0.23 \%$ for $H$. canabinus, which is quite low in both samples. This is actually low when compared to a work reported for rice husk ash of $15.7 \%$ (Efomah and Gbabo, 2015 ) and other related biomasses (kenaf grass $-17.0 \%$, neem wood $-12.9 \%$, mango wood- $11.36 \%$, and corncob$11.36 \%$ ) (Saidur et al., 2011). Fixed carbon is not necessarily equal to the total amount of carbon (ultimate carbon) in the plants because a significant amount is released as volatile hydrocarbons components. This is confirmed by the value of elemental composition reported as ultimate carbon to be $57.34 \%$ and $45.54 \%$ in $V$. colorata and $H$. canabinus respectively. This parameter provides a rough estimate of the heating value of a fuel biomass and acts as the main heat generator during combustion. Thus, the higher the carbon content of a biomass the more likely that the species would have higher heating value (Akowuah et al., 2012).

Figure 3 presents the ultimate analysis of the $V$ colorata and $H$. canabinus stem obtained from proximate analysis. Ultimate analysis involves the estimation of important chemical elements that makes up the biomass, namely; carbon $(\mathrm{C})$, hydrogen $(\mathrm{H})$, oxygen $(\mathrm{O})$, nitrogen $(\mathrm{N})$ and sulphur $(\mathrm{S})$, they are responsible for the heat generating potential of the biomasses. The results for $V$. colorata is $57.34 \%, 6.56 \%, 35.50 \%, 0.56 \%$ and $0.04 \%$ for $\mathrm{C}, \mathrm{H}, \mathrm{O}, \mathrm{N}$ and $\mathrm{S}$ respectively, while that of $H$. canabinus is $\mathrm{C}: 45.54 \%, \mathrm{H}: 4.02 \%, \mathrm{O}: 31.32 \%, \mathrm{~N}: 0.20 \%$ and S : $0.01 \%$. The results obtained is within the limits of a similar work, Chaney (2010) indicates the composition of the principal constituents as carbon ranging between 30 to $60 \%$, oxygen $30-40 \%$, hydrogen between $5-6 \%$, while nitrogen and sulphur normally makes up less than $1 \%$ of dry matter biomass.

The sizeable quantity of carbon contents with the $\mathrm{H} / \mathrm{C}$ ratio of 0.09 for $H$. Canabinus when compared to $V$. colorata having $\mathrm{H} / \mathrm{C}$ ratio of 0.11 confirms it has a higher heating value. The nitrogen contents in both plants is within the limit of $\leq 0.6 \%$ set by the Austria National Standard for Pellet and Briquettes (ONORM M 7135, 2003) and further conforms to limit of $\leq 0.3 \%$ set by the German National Standard for Fuel Pellet (DIN 51731, 1996). The sulphur contents in both samples were lower than the limits set by the Austria and German National Standards for Fuel Pellet and Briquettes (Sulphur content $\leq 0.08 \%$ ). The low sulphur and nitrogen contents in both samples are low (Figure 3 ) which is good as there will be minimal release of sulphur $\left(\mathrm{SO}_{\mathrm{X}}\right)$ and nitrogen $\left(\mathrm{NO}_{\mathrm{x}}\right)$ oxides into the atmosphere on combustion, this is confirmed from the low concentration of $\mathrm{SO}_{2}$ averaging $3.13 \mathrm{ppm}$ (Figure 6) for both samples detected from the smoke emitted. Similarly, $\mathrm{H}_{2} \mathrm{~S}$ gas detected from burning the $H$. Canabinus and $V$. colorata stems were 6.50 and $23.00 \mathrm{ppm}$ which are still low compared to EPA Maximum Standards 76.00ppm (NAAGS 2016). This further point to the fact that the use of the plants as sources of light owing to the bright flame they produced makes them environmentally friendly.

Calorific or heat values of both samples is $15 \mathrm{~mJ} / \mathrm{kg}$ for $H$. canabinus and $31.52 \mathrm{~mJ} / \mathrm{kg}$ for V. colorata. This is within the range of values obtained in coconut shell-20.00mJ/kg, groundnut shell-19.20mJ/kg, eucalyptus- $19.35 \mathrm{~mJ} / \mathrm{kg}$, softwoods- $19.80 \mathrm{~mJ} / \mathrm{kg}$, hardwoods- $19.00 \mathrm{~mJ} / \mathrm{kg}$, switch grass-19.90mJ $/ \mathrm{kg}$ (Saidur et al., 2011), but slightly below Gmelina arborea $=32.79 \mathrm{~mJ} / \mathrm{kg}$, Terminaliasuperba $=32.69 \mathrm{~mJ} / \mathrm{kg}$, Triplochitonscleroxylon $=32.79 \mathrm{~mJ} / \mathrm{kg}$ reported (Adegoke et al., 2014). The reason for high calorific value could be traced to high carbon (ultimate carbon) content suggested by researchers (Kricka et al., 2012), who recounted that the calorific value of fuel increases with similar increase in carbon level. Significance of the O: C and H: C 
ratios on the calorific value of solid fuels was reported (McKendry, 2002) using a Van Krevelen diagram from which higher proportion of hydrogen and oxygen reduces the energy value of biomass fuel than fossil fuel (coal). The average O:C and H:C ratios of 0.68 and 0.10 respectively in both samples gives a slightly low level of carbon which provide low calorific values in plants which has a remarkable influence on the heat values of the samples under study. The $\mathrm{C}$ : $\mathrm{N}$ ratio (Figure 4) will help in determining the appropriate energy conversion process in the biomasses, which will further assist in proposing a pathway for conversion of the energy of these plants into more useful energy source.

From Figure 5, the loosed, loosed oven-dry and tapped oven-dry bulk densities of $V$. colorata are higher than that of $H$. canabinus. This suggests that $V$. colorata is more likely to have higher energy per unit volume. If all other factors remain constant, it will burns for a long period of time then the H. canabinus and other biomasses used for that purpose.

\section{Conclusion}

Among the energy parameters detected in both the processed stems of $H$. canabinus and V. colorata, the volatile matter contents of $83.35 \%$ and $77.18 \%$ respectively stands out as the major parameter that justify the use of these plants by the indigenous communities as sources of light owing to the bright flame they produce. Further characterization of the volatile matters which is ongoing will reveal the chemical components that support the combustion and enhance sustainability of the bright flame.

\section{Acknowledgement}

The Royal Society of Chemistry (RSC), UK is acknowledged and appreciated for the support and assistance for this work through the Research Fund.

\section{References}

Agbro, E.B. \& Ogie N.A. (2010). A Comprehensive Review on Biomass Resources and Biofuel production. Research Journal in Engineering and Applied Sciences. 1(3): 149-155.

Chaula, Z., Said, M. \& John, G. (2014). Thermal Characterization of Pine Sawdust as Energy Source Feedstock. Journal of Energy Technology and Policy. 4. (4): 57-65.

Efomah, A. N. \& Gbabo, A. (2015). The Physical, Proximate and Ultimate Analysis of Rice Husk Briquettes Produced from a Vibratory Block Mould Briquetting Machine. International Journal of Innovative Science, Engineering \& Technology, 2(5): 814-822.

Saheed, A. M., Ahmed, S. W., Kazmi, M., Mohsin, M. \& Feroze, N. (2015). Impact of torrefaction technique on moisture contents, bulk density and calorific value of briquetted biomass. Polish Journal of Chemical Technology. 17 (2). 23-28.

Akowuah, J. O., Kemausuor, F. \& Mitchual, S. J. (2012). Physico-Chemical Characteristics and Market Potential of Sawdust Charcoal Briquettes. International Journal of Energy and Environmental Engineering, 3: 6.

Wang, T., Ding, L., Jia, Y., Jin, H., Shi, R., Zhu, L. \& Ma, Y. (2014). Simultaneous determination of six volatile components in Longhu Rendan pills using gas chromatography coupled with triple quadrupole mass spectrometry. Analytical Methods, 6: 3713-3719.

Loo, S. V. \& Koppejan, J. (2008). The Handbook of Biomass Combustion and Co-firing. Earthscan.

DIN 51731 (1996). Testing of solid fuels - compressed untreated wood, requirements and testing. Berlin, Germany:Deutsches Institut für [Online] Normung. Available: https://standards.globalspec.com/std/497774/din-51731 (December 5, 2016).

ONORM M 7135 (2003). Compressed wood or compressed bark in natural state, pellets and briquettes. Requirements and test specifications. Vienna, Austria: Österreichisches. [Online] Available: https://infostore.saiglobal.com/en-gb/standards/onorm-m-7135-2000-712560/ (January 18, 2017).

Godbout, S., Palacios, J. H., Larouche, J. P., Brassard, P. \& Pelletier, F. (2012). Bilan énergétique, émissions gazeuses et particulaires de la combustion de la biomasse agricole à la ferme. 251 .

Saidur, R., Abdelaziz, E.A., Dermibas, A., Hossain, M. S. \& Mekhilef, S. (2011). A review on biomass as a fuel for boilers. Renewable Sustainable Energy Reviews. 15(5): 2262-2289P.

Chaney, J. (2010). Combustion characteristics of biomass briquettes. Unpublished PhD studies. [Online] Available: http://etheses.nottingham.ac.uk/1732/1/Combustion_Characteristics_of_Biomass_Briquettes. pdf (June 12, 2016).

Musa, N. A. (2007). Comparative Fuel Characterization of Rice Husk and Groundnut Shell Briquettes. NJREDl.6(4): 23-27.

United State Environmental Protection Agency -USEPA (2016). NAAGS Table. [Online] Available: https://19january2017snapshot.epa.gov/criteria-air-pollutants/naaqs-table_html (February 7, 2017)

Adegoke, A. K., Abdullah, W. H., Hakimi, M. H. \& Yandoka, B, M. S. (2014). Geochemical characterisation of Fika Formation in the Chad (Bornu) Basin, northeastern Nigeria: Implications for depositional environment 
and tectonic setting. Applied Geochemistry. 43: 1-12.

Kricka, T., Bilandzija, N., Jurisic, V., Voca, N. \& Matin, A. (2012). Energy analysis of main residual biomass in Croatia. African Journal of Agricultural Research. 7(48): 6383-6388.

McKendry, P. (2002). Energy production from biomass. Part 3. Gasification technologies. Bioresource Technology; 83: 55-63.

First A. Author (M'76-SM'81-F'87) and the other authors may include biographies at the end of regular papers. Biographies are often not included in conference-related papers. This author became a Member (M) of Association XXXX in 1976, a Senior Member (SM) in 1981, and a Fellow (F) in 1987. The first paragraph may contain a place and/or date of birth (list place, then date). Next, the author's educational background is listed. The degrees should be listed with type of degree in what field, which institution, city, state, and country, and year degree was earned. The author's major field of study should be lower-cased.

Second A. Author (M'76-SM'81-F'87) and the other authors may include biographies at the end of regular papers. Biographies are often not included in conference-related papers. This author became a Member (M) of Association XXXX in 1976, a Senior Member (SM) in 1981, and a Fellow (F) in 1987. The first paragraph may contain a place and/or date of birth (list place, then date). Next, the author's educational background is listed. The degrees should be listed with type of degree in what field, which institution, city, state, and country, and year degree was earned. The author's major field of study should be lower-cased.

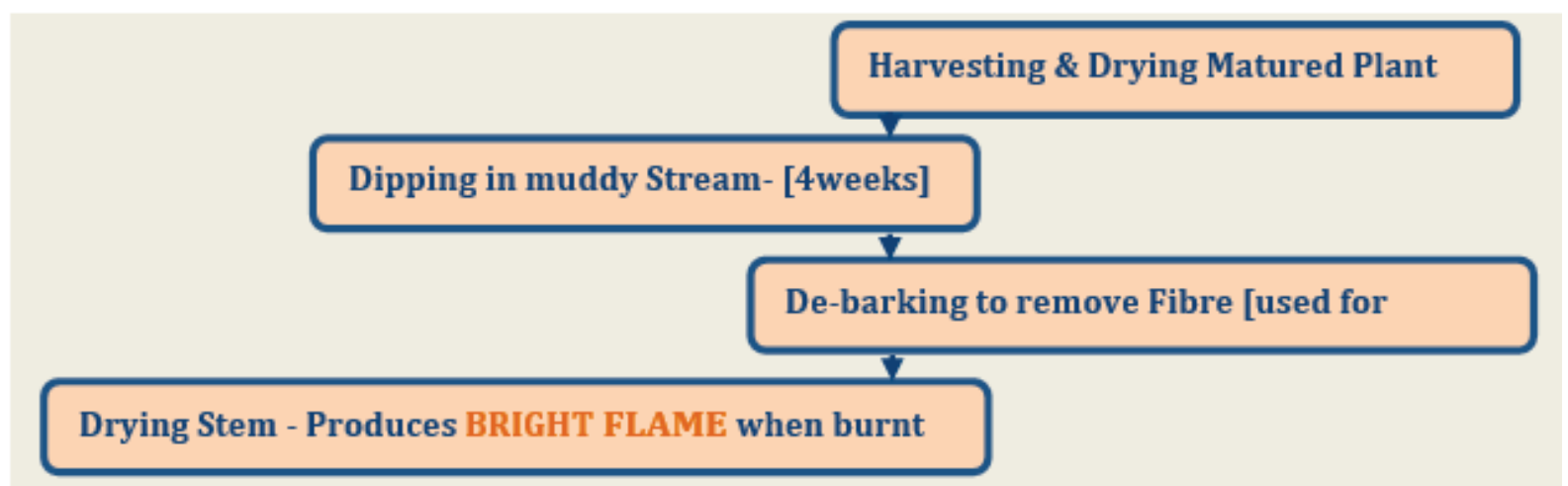

Figure 1: Flow Chart for traditional processing of the biomasses.

\begin{tabular}{|c|c|}
\hline \multirow[b]{2}{*}{ Organic matter } & - H. canabinus \\
\hline & \begin{tabular}{l|l}
60.65 \\
\end{tabular} \\
\hline Dry matter & 90.52 \\
\hline Fixed carbon & 0.238 .69 \\
\hline Volatile matter & $\begin{array}{r}77.18 \\
83.35\end{array}$ \\
\hline Ash & $\begin{array}{r}4.65 \\
8.6\end{array}$ \\
\hline Moisture & $\begin{array}{r}9.48 \\
.53\end{array}$ \\
\hline Figr & 2: Proximate analysis of $H$. canabinus and $V$. colorata stems (\%) \\
\hline
\end{tabular}




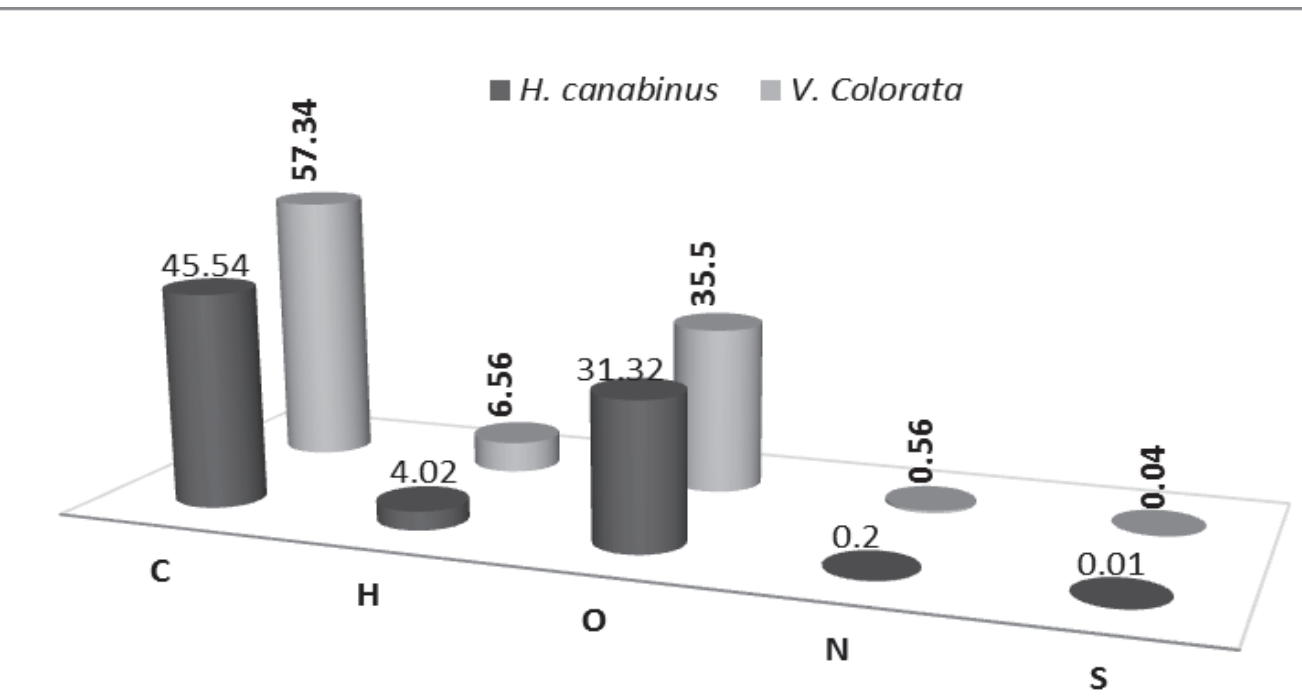

Figure 3: Ultimate Analysis of V. canabinus and V. colorata (\%)

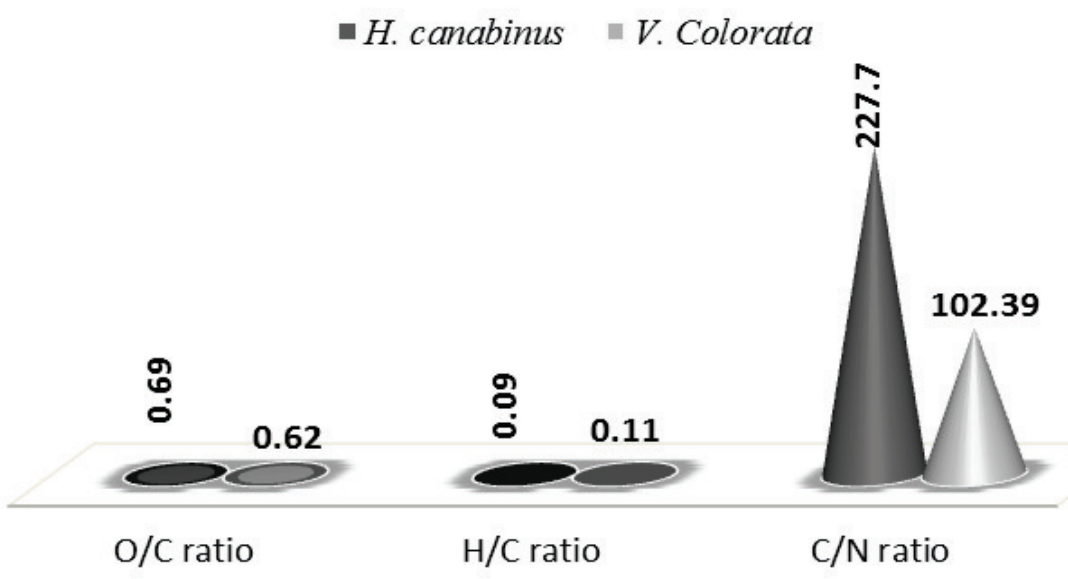

Figure 4: $\mathrm{O} / \mathrm{C}, \mathrm{H} / \mathrm{C}$ and $\mathrm{C} / \mathrm{N}$ ratios of $H$. Canabinus and $V$. Colorata

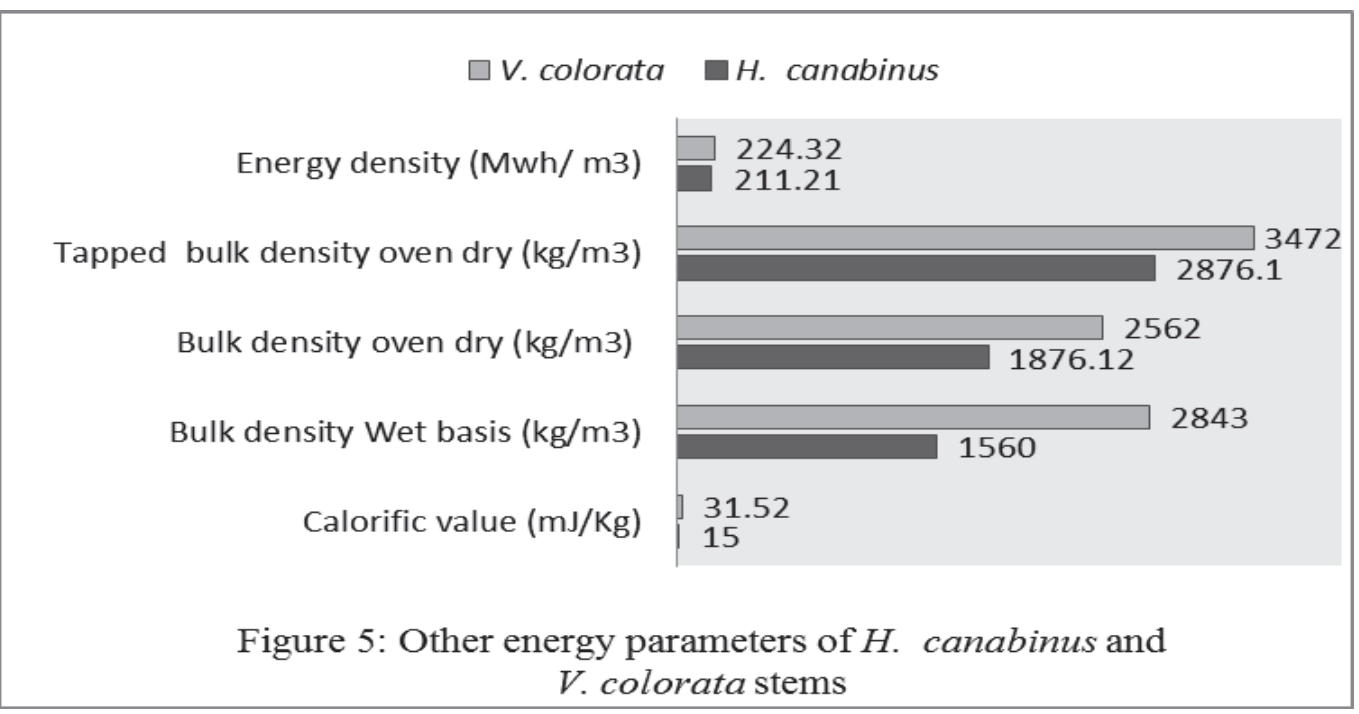




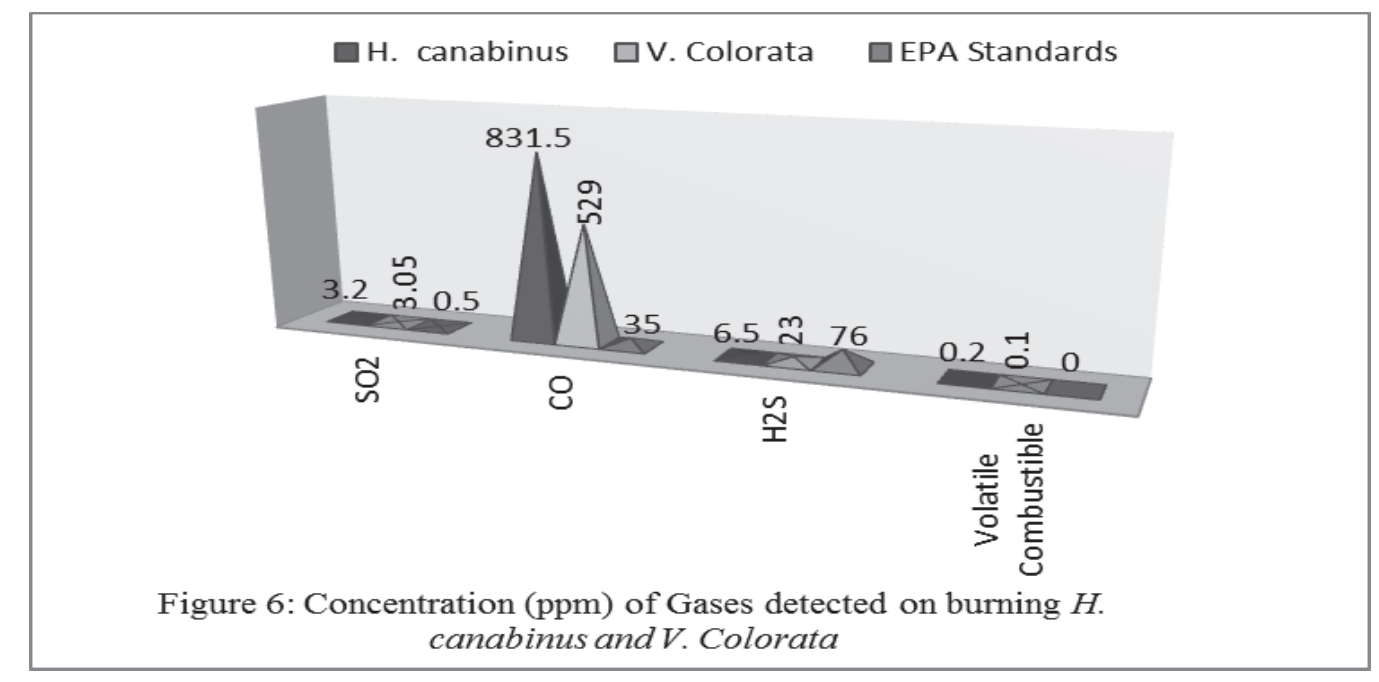

